\title{
Editorial: The Space in Between, or, Why ITAL Matters
}

\section{The Space in Between}

In my opinion, ITAL has an identity crisis. It seems to try in many ways to be scholarly like JASIST, but LITA simply isn't as formal a group as ASIST. On the other end of the spectrum, Code4Lib is very dynamic, informal and community-driven. ITAL kind of flops around awkwardly in the space in between.

- comment by a respondent to

ITAL's reader survey, December 2009

Last December and January, you, the readers of Information Technology and Libraries were invited to participate in a survey aimed at helping us to learn your likes and dislikes about ITAL, and where you'd like to see this journal go in terms of several important questions. The responses provide rich food for reflection about ITAL, its readers, what we do well and what we don't, and our future directions. Indeed, we're still digesting and discussing them, nearly a year after the survey. I'd like to use some of my editorial space in this issue to introduce, provide an overview, and highlight a few of the most interesting results. I strongly encourage you to access the full survey results, which I've posted to our weblog ITALica (http:/ / ital-ica.blogspot.com/); I further invite you to post your own thoughts there about the survey results and their meaning.

We ran the survey from mid-December to mid-January. A few responses trickled in as late as mid-February. The survey invitation was sent to the 2,614 LITA personal members; nonmembers and ITAL subscribers (most of whom are institutions) were excluded. We ultimately received 320 responses-including two from individuals who confessed that they were not actually LITA members-for a response rate of 12.24 percent. Thus the findings reported below reflect the views of those who chose to respond to the survey. The response rate, while not optimal, is not far from the 15 percent that I understand LITA usually expects for its surveys. As you may guess, not all respondents answered all questions, which accounts for some small discrepancies in the numbers reported.

\section{Who are we?}

In analyzing the survey responses, one of the first things one notices is the range and diversity of ITAL's reader base, and by extension, of LITA's membership. The largest groups of subscribers identify themselves either as traditional systems librarians (58, or 18.2 percent) or web services/development librarians (31, or 9.7 percent), with a further cohort of 7.2 percent (23) composed of those working with electronic resources or digital projects. But more than 20 percent (71) come from the ranks of library directors and associate directors. Nearly 15 percent (47) identify their focus as being in the areas of reference, cataloguing, acquisitions, or collection development. See figure 1 .

The bottom line is that more than a third of our readers are coming from areas outside of library IT. A couple of other demographic items:

- While nearly six in ten respondents $(182$, or 57.6 percent) work in academic libraries, that still leaves a sizable number (134, or 42.3 percent) who don't. More than 14 percent (45) of the total 316 respondents come from the public library sector.

- Nearly half (152, or 48.3 percent) of our readers indicated that they have been with LITA for five years or fewer. Note that this does not necessarily indicate the age or number of years of service of the respondents, but it's probably a rough indicator. Still, I confess that this was something of a surprise to me, as I expected larger numbers of long-time members. And how do the numbers shake out for us old geezers? The 6-10 and greater-than-15-years cohorts each composed about 20 percent of those responding; interestingly, only 11.4 percent (36) answered that they'd been LITA members for between 11 and 15 years. Assuming that these numbers are an accurate reflection of LITA's membership, I can't help but wonder about the explanation for this anomaly." See figure 2.

\section{How are we doing?}

Question 4 on the survey asked readers to respond to several statements:

\section{"It is important to me that articles in ITAL are peer- reviewed."}

More than 75 percent (241, or 77.2 percent) answered that they either "agreed" or "strongly agreed."

\section{"ITAL is timely."}

More than seven in ten respondents (228, or 73.0 percent) either "agreed" or "strongly agreed" that ITAL is timely. Only 27 (8.7 percent) disagreed. As a technology-focused journal, where time-to-publication is always a sensitive issue, I expected more dissatisfaction on this question (and no, that doesn't mean that I don't worry about the nine percent who believe we're too slow out of the gate).

Marc Truitt (marc.truitt@ualberta.ca) is Associate University Librarian, Bibliographic and Information Technology Services, University of Alberta Libraries, Edmonton, Alberta, Canada, and Editor of ITAL. 
"I use information from ITAL in my work and/ or I find it intellectually stimulating."

By a nearly identical margin to that regarding timeliness, ITAL readers (226, or 72.7 percent) either "agreed" or "strongly agreed" that they use ITAL in their work or find its contents stimulating.

\section{"ITAL is an important benefit of LITA mem- bership."}

An overwhelming majority (248, or 79.78 percent) of respondents either "agreed" or "strongly agreed" with this statement. ${ }^{1}$ This perception clearly emerges again in responses to the questions about whether readers would drop their LITA membership if we produced an electronic-only or open-access ITAL (see below).

\section{Where should we be going?}

Several questions sought your input about different options for ITAL as we move forward. Question 7, for example, asked you to rank how frequently you access ITAL content via several channels, with the choices being "print copy received via membership," "print copy received by your institution/library," "electronic copy from the ITAL website," or "electronic copy accessed via an aggregator service to which your institution/library subscribes (e.g., Ebsco)." The choice most frequently accessed was the print copy received via membership, at 81.1 percent (228).

Question 8 asked about your preferences in terms of ITAL's publication model. Of the 307 responses, 60.6 percent (186) indicated a preference for continuance of the present arrangement, whereby we publish both paper and electronic versions simultaneously. Four in ten respondents preferred that ITAL move to publication in electronic version only. ${ }^{2}$ Of those who favored continued availability of paper, the great majority (159, or 83.2 percent) indicated in question 9 that they simply preferred reading ITAL in paper. Those who advocate moving to electronic-only do so for more mixed reasons (question 10), the most popular being cost-effectiveness, timeliness, and the environmental friendliness of electronic publication. A final question in this section asked that you respond to the statement "If ITAL were to become an electronic-only publication I would continue as a dues-paying member of LITA." While a reassuring 89.8 percent (273) of you answered in the affirmative, 9.5 percent (29) indicated that you

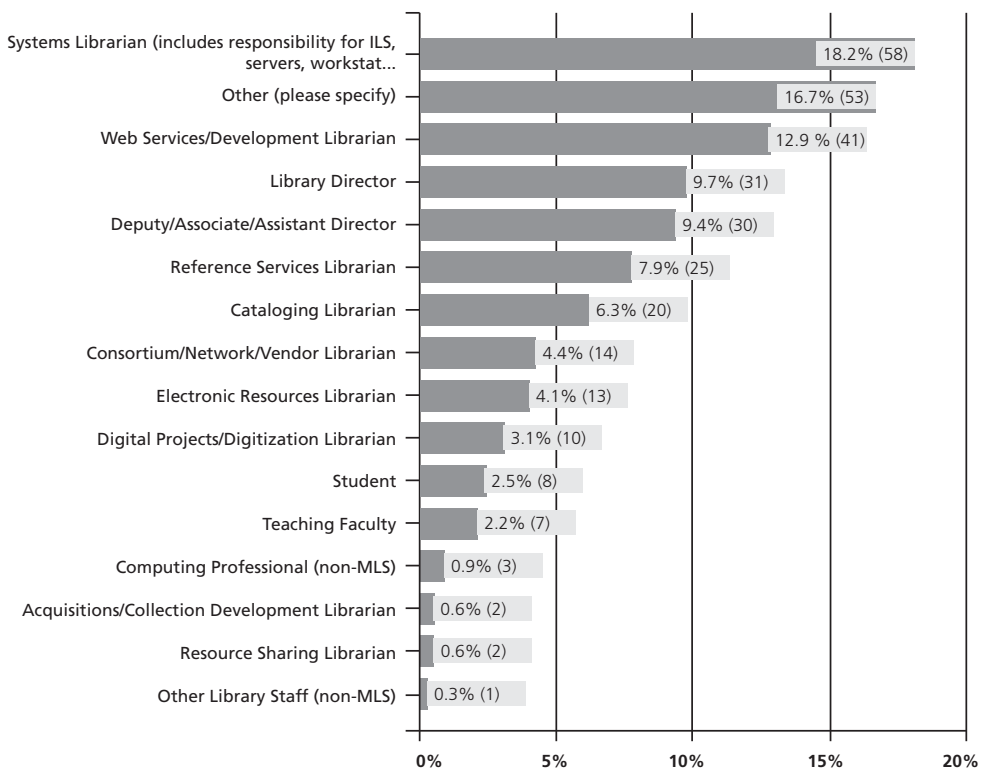

Figure 1. Professional Position of LITA Members

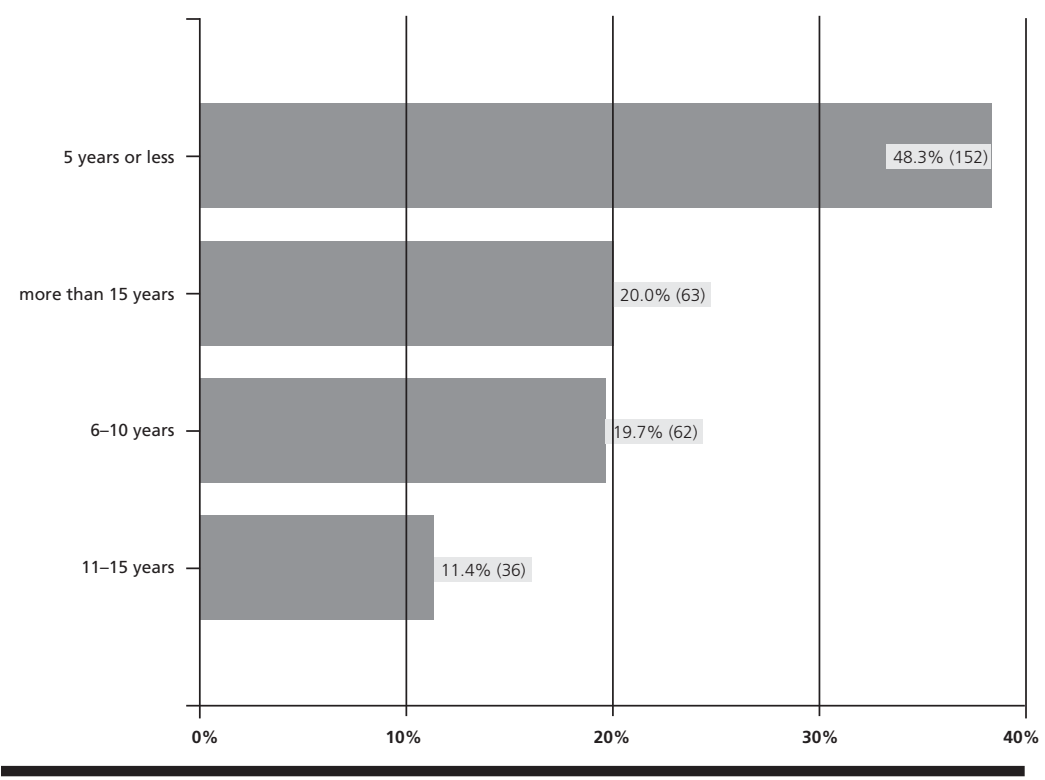

Figure 2. Years of LITA Membership

would likely quit LITA, with narrative explanations that clearly underscore the belief that ITAL-especially a paper ITAL-is viewed by many as an important benefit of membership. The following comments are typical:

- "LITA membership would carry no benefits for me."

- "Dues should decrease, though." [from a respondent who indicated he or she would retain LITA 
membership]

- "ITAL is the major benefit to me as we don't have funds for me to attend LITA meetings or training sessions."

- "The paper journal is really the only membership benefit I use regularly."

- "Actually my answer is more, 'I don't know.' I really question the value of my LITA membership. ITAL is at least some tangible benefit I receive. Quite honestly, I don't know that there really are other benefits of LITA membership."

Question 12 asked about whether ITAL should continue with its current delayed open-access model (i.e., the latest two issues embargoed for non-LITA members), or go completely open-access. By a three-to-two margin, readers favored moving to an open-access model for all issues. In the following question that asked whether respondents would continue or terminate LITA membership were ITAL to move to a completely open-access publication model, the results were remarkably similar to those for the question linking print availability to LITA membership, with the narrative comments again suggesting much the same underlying reasoning.

In sum, the results suggest to me more satisfaction with ITAL than I might have anticipated; at the same time, I've only scratched the surface in my comments here. The narrative answers in particular-which I have touched on in only the most cursory fashion-have many things to say about ITAL's "place," suggestions for future articles, and a host of other worthy ideas. There is as well the whole area of crosstabbing: some of the questions, when analyzed with reference to the demographic answers in the beginning of the survey, may highlight entirely new aspects of the data. Who, for instance, favors continuance of a paper ITAL, and who prefers electronic-only?

But to come back to that reader's comment about ITAL and "the space in between" that I used to frame this discussion (indeed, this entire column): to me, the demographic responses-which clearly show ITAL has a substantial readership outside of library IT-suggest that that "space in between" is precisely where ITAL should be. We may or may not occupy that space "awkwardly," and there is always room for improvement, although I hope we do better than "flop around"! The results make clear that ITAL's readers-who would be you!-encompass the spectrum from the tech-savvy early-career reader of Code4Lib Journal (electronic-only, of course!) to the library administrator who satisfies her need for technology information by taking her paper copy of ITAL along when traveling. Elsewhere on that continuum, there are reference librarians and catalogers wondering what's new in library technology, and a traditional systems librarian pondering whether there is an open-source discovery solution out there that might breathe some new life into his lipstick-on-a-pig ILS. Somewhere else there's a library blogger who fends off bouts of insomnia by reading "wonky" ITAL papers in the wee hours of the morning. And that ain't the half of it, as they say.

In short-in terms of readers, interests, and preferences-"the space in between" is a pretty big niche for ITAL to serve. We celebrate it. And we'll keep trying our best to serve it well.

\section{Departures}

As I write these lines in late-September, it's been a sad few weeks for those of us in the ITAL family. In mid-August, former ITAL editor Jim Kopp passed away following a battle with cancer. Last week, Dan Marmion-Jim's successor as editor (1999-2004) — and a dear friend to many of us on the current ITAL editorial board-also left us, the victim of a malignant brain tumor. I never met Jim, but LITA President Karen Starr eulogized him in a posting to LITA-L on August 16, 2010. ${ }^{3}$ I noted Dan's retirement due to illness in this space in March. ${ }^{4}$

I first met Dan in the spring of 2000, when he arrived at Notre Dame as the new associate director for Information Systems and Digital Access (I think the position was differently titled then) and, incidentally, my new boss. Dan arrived only six weeks after my own start there. Things at Notre Dame were unsettled at the time: the Libraries had only the year before successfully implemented ExLibris' Aleph500 ILS, the first North American site to do so. While ExLibris moved on to implementations at McGill and the University of Iowa, we at Notre Dame struggled with the challenges of supporting and upgrading a system then new to the North American market. It was not always easy or smooth, but throughout, Dan always maintained an unflappable and collegial manner with ExLibris staff and a quiet but supportive demeanor toward those of us who worked for him. I wish I could say that I understood and appreciated this better at the time, but I can't. I still had some growing ahead of me-I'm sure that I still do.

Dan was there for me again as an enthusiastic reference when I moved on, first to the University of Houston in 2003 and then to the University of Alberta three years later. In these jobs I'd like to think I've come to understand a bit better the complex challenges faced by senior managers in large research libraries; in the process, I know I've come to appreciate Dan's quiet, knowledgeable, and hands-off style with department managers. It is one I've tried (not always successfully) to cultivate.

While I was still at Notre Dame, Dan invited me to join the editorial board of Information Technology and Libraries, a group which over the years has come to include many "Friends of Dan," including Judith Carter (quite possibly the world's finest managing editor), Andy Boze (ITAL's 
webmaster), and Mark Dehmlow. While Dan left ITAL in 2004, I think that he left the journal a wonderful and lasting legacy in these extremely capable and dedicated folks.

My fondest memories of Dan concern our shared passion for model trains. I remember visiting a train show in South Bend with him a couple of times, and our last time together (at the ALA Midwinter Meeting in Denver two years ago) was capped by a snowy trek with ExLibris' Carl Grant, another model train enthusiast, to the Mecca of model railroading, Caboose Hobbies. Three boys off to see their toys—oh, exquisite bliss!

I don't know whether ITAL or its predecessor JOLA have ever reprinted an editorial, but while searching the archives to find something that would honor both Jim and Dan, I found a piece that I hope speaks eloquently of their contributions and to ITAL's reason for being. Dan's editorial, "Why Is ITAL Important?" originally published in our June 2002 issue, appears again immediately following this column. I think its message and the views expressed therein by Jim and Dan remain as valid today as they were in 2002. They also may help to frame my comments concerning our reader survey in the previous section.

Farewell, Jim and Dan. You will both be sorely missed.

\section{Notes and References}

1. A number of narrative answers to the survey make it clear that ITAL readers who are LITA members perceive a link between membership and receiving the journal. Many of them appear to infer that a portion of their LITA dues, then, are earmarked for the publication and mailing of ITAL. Sadly, this is not the case. In years past, ITAL's income from advertising paid the bills and even generated additional revenue for LITA coffers. Today, the shoe is on the other foot because of declining advertising revenue, but ITAL is still expected to pay its own way, which it has failed to do in recent years. But to those who reasonably believe that some portion of their dues is dedicated to the support of ITAL, well, t'ain't so. Bothered by this? Complain to the LITA board.

2. As a point of comparison, consider the following results from the 2000 ITAL reader survey. Respondents were asked to rank several publishing options on a scale of 1 to 3 (with $1=$ most preferred option and 3 = least preferred option):

ITAL should be published simultaneously as a print-onpaper journal and an electronic journal $(N=284)$ :

$1=169(59.5 \%) ; 2$ = $93(32.7 \%) ; 3=22(7.7 \%)$

ITAL should be published in an electronic form only $(N=293)$ :

$1=55(18.8 \%) ; 2=61(20.8 \%) ; 3=177(60.4 \%)$

In other words, then as now, about $60 \%$ of readers preferred paper and electronic to electronic-only.

3. Karen Starr, "FW: [Libs-Or] Jim Kopp: Celebration of Life," online posting, Aug. 16, 2010, LITA-L, http://lists.ala. org/sympa/arc/lita-1/2010-08/msg00079.html (accessed Sept. $29,2010)$.

4. Marc Truitt, "Dan Marmion," Information Technology \& Libraries 29 (Mar. 2010): 4, http://www.ala.org/ala/mgrps/ divs/lita/ital/292010/2901mar/editorial_pdf.cfm (accessed Sept. 29, 2010). 